\title{
CULTURA ECONÔMICA DO EMPREENDIMENTO ÉTNICO: CAMINHOS DA IMIGRAÇÃO AO EMPREENDEDORISMO
}

\author{
Marylin Halter \\ Boston University
}

Dentre minhas áreas de especialização está a imigração recente para os Estados Unidos, com especial interesse na formação da identidade étnica e no papel dos imigrantes e dos americanos étnicos no mercado e nas qualidades de fornecedores e consumidores. Explorarei duas facetas diferentes da relação entre a educação para o empreendedorismo e a experiência dos imigrantes. Começarei por um exame da cultura econômica do empreendedorismo étnico e encerrarei com uma discussão do impacto educacional em potencial das tendências, relacionando-as com a reação da América corporativa aos deslocamentos dramáticos e globalizados do panorama etnorracial dos Estados Unidos.

Há mais de 180 anos, a sociedade americana atingiu seu ápice em níveis de auto-emprego. Durantes as décadas de 1820 e 1830, grandes mudanças religiosas coincidiram com uma ampla explosão da atividade dos pequenos negócios, criando o que foi chamado "milênio dos lojistas", especialmente no Nordeste dos Estados Unidos. Com a expansão da economia de mercado do século XIX, a proporção de americanos brancos livres e proprietários de seus próprios negócios chegou a $80 \%$. Desde então, esse tipo de empreendedorismo declinou constantemente. Mas o crédito e a significância do empreendedorismo étnico na vida socioeconômica americana recente, um setor da economia marcado por pequenos empreendimentos tocados por imigrantes e suas famílias, é um fenômeno que gerou grande interesse contemporâneo por um amplo espectro político e ideológico e entre estudiosos, educadores, formadores de políticas e ativistas comunitários.

A maioria dos acadêmicos das ciências sociais previra que as pequenas empresas praticamente desapareceriam dos Estados Unidos ao fim do século XX; outros projetaram que a significância da etnia em relação ao sucesso econômico diminuiria muito a essa altura do capitalismo avançado. É interessante observar que todos os gigantes da sociologia moderna, inclusive Karl Marx e Max Weber, subestimaram a vitalidade do empreendedorismo no Estado moderno, e nenhum deles contribuiu com modelos teóricos capazes de explicar sua importância contínua. Assim, ergueuse um improvável consenso entre os estudiosos, à direita, à esquerda e ao centro, de que o empreendedorismo simplesmente viria a ser obsoleto nas economias avançadas. Porém, desde a década de 1880 os imigrantes têm representação desproporcional entre os pequenos empreendimentos americanos, e a última onda de recém- chegados ao país tem, mais uma vez, injetado uma nova dose de vitalidade nesse setor da economia.

O espírito empreendedor tem se mostrado surpreendentemente resistente na economia pós-industrial, especialmente no caso dos empreendimentos de base étnica. Com efeito, um estudo nacional lançado pela Fundação Kauffman em maio de 2006 revelou que os imigrantes superam em muito os americanos natos em termos de atividade empreendedora. A taxa de empreendedorismo dos imigrantes em 2005 era de $0,35 \%$, contra $0,28 \%$ dos americanos natos. Em outras palavras, aproximadamente 350 de cada 100 mil imigrantes fundaram um negócio por mês em 2005, contra 280 de cada 100 mil americanos natos. De fato, são as pequenas empresas - e não as megacorporações - o mais dinâmico gerador de empregos na economia americana contemporânea.

Principalmente para os novos imigrantes que enfrentam barreiras lingüísticas ou carecem das credenciais educacionais necessárias e, portanto, estão afastados do mercado de trabalho secundário e se vêem impossibilitados de obter emprego adequado ou aceitável, o empreendedorismo pode ser um caminho viável para o êxito econômico. Tanto histórica quanto atualmente, determinados grupos de 
imigrantes criaram para si nichos étnicos, um termo que se refere à participação desproporcional de minorias raciais e étnicas em determinadas funções, pontos da economia em que, por qualquer razão, um grupo étnico específico desfruta de vantagem. Entre os que exibiram habilidades empreendedoras que resultaram no estabelecimento de negócios de nicho específicos estão os coreanos em quitandas, chineses em lavanderias, judeus na indústria de confecções ou cambojanos em lojas de donuts.

Atualmente estou pesquisando imigrantes e refugiados recentes da África ocidental para os Estados Unidos, e um bom exemplo contemporâneo do caminho empreendedor e da dinâmica da formação de um nicho étnico para uma nova população imigrante está nas habilidades culturais transplantadas de africanas francófonas, que se ocupam de salões de beleza especializados no trançamento de cabelos. Os proprietários desses estabelecimentos também ilustram o processo de readequação que tão freqüentemente ocorre na experiência imigrante. Muitas dessas mulheres ocupavam posições liberais no Senegal, mas chegaram desprovidas das habilidades lingüísticas necessárias para ocupar os cargos para os quais foram treinadas ou sequer competir por empregos. Assim, começam seus negócios de trançamento em seus próprios lares como parte da economia oculta, enquanto tomam aulas noturnas de inglês. Uma vez proficientes na nova língua, podem transportar seu negócio de casa para uma loja e estabelecer um salão profissional.

Como uma parcela estratégica dos pequenos negócios é ocupada por empreendedores étnicos, um melhor entendimento desses proprietários pode ser de grande utilidade. A pesquisa sobre o empreendedorismo étnico sublinha a maneira como características culturais distintivas contribuem para o sucesso de um empreendimento e esclarece que a etnia é um fator da vida econômica. Isso ocorre no marketing de produtos étnicos, na contratação de compatriotas, no relacionamento com clientes co-étnicos, no capital cultural gerado por meio de recursos ou estratégias de capitalização de fundo étnico. A cooperação entre imigrantes, misturando comportamentos tradicionais e modernos, pode resultar numa potente poção econômica para os empreendedores étnicos.

Se os empreendedores imigrantes e étnicos ocupam lugar tão significativo na economia, como então aprendem a abrir e sustentar seus empreendimentos? Tal conhecimento é quase sempre obtido por vias não acadêmicas, sendo que duas trajetórias principais assumem o lugar da educação forma. A primeira é resultado de treinamento e mentoria práticos; a outra, especialmente quando o imigrante tem status de refugiado, se dá pela exploração de programas de treinamento patrocinados pelo governo. Ivan Light, importante estudioso do campo do empreendedorismo étnico, defende o uso de outros critérios, além da medida padronizada de diferenciais relativos de remuneração, como indicadores de sucesso de uma economia étnica. Ele observa que tais economias servem como campos de treinamento para o empreendedorismo, e, portanto, os ganhos não precisam necessariamente realizar-se em termos monetários apenas. Alguns estudos demonstram que aqueles que estão empregados na economia étnica têm maiores chances do que os demais de vir a se tornar, eles mesmos, auto-empregados. Nesse sentido, Light refere-se à economia étnica como uma "escola de empreendedores". De maneira semelhante, Alejandro Portes e Robert Bach, em seu estudo com imigrantes cubanos e mexicanos, identificaram um padrão comparável.
Os resultados dos diversos estudos de caso que conduzi em Boston para um livro sobre empreendimentos étnicos que publiquei há alguns anos também fornecem forte respaldo ao argumento de que o valor do empreendedorismo étnico pode ser avaliado em dimensões mais amplas do que os lucros, de prazo relativamente curto. Esses tipos de formações, pelo contrário, podem exercer um efeito multiplicador. Um dos resultados da pesquisa foi a indicação da importância do papel de um empreendimento étnico como escola para futuros empreendedores. Isso não se traduz, necessariamente, numa simples correspondência $1: 1$, em que todos os empregados de um empreendimento étnico tornamse proprietários, ou em que todos os filhos de empreendedores crescem e assumem o negócio da família, muito embora haja numerosos exemplos dessas duas correlações.

A questão é que, de modo geral, a economia étnica fornece uma plataforma para que tanto os empregados co-étnicos quanto a segunda geração se integrem na sociedade em posições vantajosas, independentemente de se dedicarem ou não aos negócios. Entre os gregos, por exemplo, é bastante comum o padrão de imigrantes recémchegados que buscam emprego em estabelecimento co-étnico, aprendem como funciona o negócio e, então, abrem seu próprio empreendimento. Uma tendência freqüente entre os filhos de empreendedores gregos, judeus da ex-União Soviética, refugiados do Khmer (cambojanos), haitianos e oriundos das Antilhas Britânicas é buscar ocupações liberais em vez de seguir os passos dos pais e manter o negócio da família. Mas são os recursos econômicos e sociais decorrentes dos negócios de família bem-sucedidos que permitem aos filhos de imigrantes atingir níveis de educação mais elevados e obter empregos liberais. 
Além disso, os padrões de empreendedorismo podem variar com o passar das gerações. Por exemplo, os judeus de hoje não se dedicam mais a esse tipo de empreendimento, como o faziam na virada do século passado, quando fundaram pequenos negócios em tão grande número, mas ainda existe elevada taxa de auto-emprego. Hoje, números proporcionalmente mais elevados se auto-empregam como profissionais liberais independentes, especialmente médicos e advogados. Quando o filho do proprietário de uma deli russo-judaica cresce e se torna médico, certa vitalidade empreendedora sobrevive à transição, e essa força não é mera sobrevivência cultural, mas também sua vantagem econômica. Tais esforços levam a uma base econômica de solidariedade étnica, mas a definição de auto-emprego mudou com o tempo: tomou-se uma nova avenida de mobilidade ascendente. Entretanto, tudo decorre da exposição inicial à economia étnica, e traz retorno tanto aos próprios indivíduos quanto à riqueza geral da comunidade étnica. Esse efeito multiplicador encontra precedentes históricos, como já se demonstrou para as vias de mobilidade judaica e japonesa, duas minorias que estão entre as de maior sucesso nos Estados Unidos. Exemplos históricos e contemporâneos comprovam a veracidade da afirmativa de Light, de que a economia étnica pode ser vista como um trampolim para recompensas futuras, tanto econômicas quanto sociais, e não apenas em termos de ganhos relativos imediatos em comparação com os do mercado de trabalho em geral. Por fim, esses estudos demonstram que o empreendimento étnico não é apenas uma "escola de empreendedores", mas, em termos mais gerais, é uma escola de mobilidade social e um contexto de solidariedade a partir do qual os indivíduos adquirem confiança para aventurar-se no corpo mais amplo da sociedade americana.

Além de "pegar o jeito" por meio de experiência direta, na qualidade de segunda geração de uma família imigrante ou de empregados compatriotas de proprietários imigrantes, o treinamento oferecido por agências governamentais para imigrantes que desejam ter seu próprio negócio está disponível principalmente para refugiados, não para imigrantes econômicos. Os refugiados que hoje adentram os Estados Unidos o fazem legalmente, apoiados pela da Lei de Refugiados de 1980, que os classifica como pessoas que fugiram de seus países de origem por causa de perseguição ou do temor de perseguição devido a raça, religião, nacionalidade, opinião política ou pertinência a um grupo social específico. A lei de 1980 criou o Programa Federal de Acolhimento de Refugiados, e determina expressamente a oferta de assistência para ajudá-los a atingir auto-suficiência econômica $o$ mais rapidamente possível após sua chegada aos Estados Unidos. Aqueles que preenchem os requisitos para serem considerados refugiados fazem jus a ajuda federal sob a forma de dinheiro e assistência médica, além de diversas formas de assistência social, como aulas de inglês, apoio ao ajuste social, preparo para a cidadania e naturalização, e serviços de emprego que podem incluir iniciativas como programas governamentais de treinamento para a microempresa.

Por exemplo, a Associação NovaYorkina de Novos Americanos (New York Association for New Americans NYANA) reconhece que muitos imigrantes sonham fundar ou expandir uma pequena empresa e há 10 anos estabeleceu um Centro de Negócios para Novos Americanos, para ajudá-los a realizar esse sonho. Sob os auspícios do Programa de Desenvolvimento de Microempresas, além do desembolso de microempréstimos a refugiados, o Centro ajuda muitos negócios em diversos estágios de desenvolvimento, fornecendo treinamento e suporte técnico, oferecendo aulas de Introdução ao Comércio Eletrônico, Como Cuidar de Crianças, Comercialização de Comida Caseira e Marketing na Internet. O Centro de Negócios da NYANA também opera o maior Programa de Desenvolvimento Individual do estado de Nova York. Das 799 famílias de refugiados de baixa renda inscritos no programa, 643 se formaram. A NYANA trabalha com o Departamento de Administração de Pequenos Negócios dos Estados Unidos, com doações de empresas do setor privado como a American Express e o Citigroup. Em 2003, o Centro recebeu uma bolsa de tecnologia da Hewlett Packard Company que lhe permitiu estabelecer dois avançados laboratórios de tecnologia em Nova York, um em Manhattan e o outro em Jackson Heights, no Queens.

Outra iniciativa semelhante - esta na região metropolitana de Atlanta, Geórgia - é um programa de treinamento empreendedor que se concentra em refugiadas. Muitas refugiadas e imigrantes chegam aos Estados Unidos com experiência em administração de pequenos negócios em seus países natais ou com diplomas profissionais. No entanto, têm dificuldade em explorar suas experiências e seus títulos nos Estados Unidos, e se vêem presas a empregos de baixa remuneração e com poucas oportunidades de progresso. A Rede de Refugiadas (Refugee Women's Network - RWN) de Atlanta, como outros programas de microempresas de todo o país, procura fornecer às imigrantes e refugiadas as habilidades necessárias para fundar ou expandir pequenos negócios. Programas desse tipo têm por meta ajudar essas mulheres a adquirir confiança e atingir a auto-suficiência econômica. 
O primeiro passo do programa de microempresas da RWN é um curso de seis semanas sobre a redação de um plano de negócio. A RWN suplementa as aulas com acompanhamento pós-curso para fornecer incentivo e assistência técnica. Também facilita a formação de redes de apoio compostas de graduadas do programa e concede microempréstimos.

O objetivo da RWN é conceber um programa que canalize o ímpeto empreendedor dessas mulheres e alavanque suas habilidades e seus talentos para a obtenção de algo tangível. Simultaneamente, acomoda as muitas restrições que as mulheres enfrentam na qualidade de recém-chegadas, como a adaptação a uma nova cultura, o aprendizado do inglês, a busca de um lugar para morar e a luta para pagar as contas. Embora a RWN há muitos anos esteja envolvida com treinamento de liderança para imigrantes e refugiadas, não havia se concentrado em treinamento vocacional ou empresarial até 2001, quando lançou seu programa de microempresas. O programa surgiu de pedidos de refugiadas que haviam participado do Treinamento de Liderança da RWN e queriam ajuda para fundar seus próprios negócios. Aproximadamente 200 mulheres já passaram pelo curso de treinamento em planejamento de negócios desde sua fundação, e, segundo a RWN, cerca de um terço delas fundou, expandiu ou reforçou um negócio. Para atrair participantes, a RWN se envolve com a comunidade. A instituição se fia em contatos com programas de emprego de outras agências, anúncios em jornais e estações de rádio étnicas, folhetos e, principalmente, propaganda de boca em boca.

A RWN sabia que as mulheres que se matriculavam em seus cursos estariam embarcando numa jornada longa e por vezes solitária. Em seu caminho, precisariam de assistência financeira e técnica. Também precisariam de apoio moral. Frente a isso, a RWN contratou em 2005 um consultor para prestar serviços de acompanhamento e reunir as graduadas do programa numa rede de apoio. O consultor fornece assistência técnica individualizada, ajuda a aproximar pessoas que estejam em busca de sócios e aconselha mulheres em busca de educação, treinamento ou certificação. Em 2005 a RWN também lançou um programa de microcrédito voltado predominantemente para graduadas do programa. A RWN concede pequenos empréstimos que vão de US\$250 a US\$ 5.000 para ajudar as empreendedoras na construção de seus negócios.

Outras organizações nos âmbitos estadual e federal que fornecem assistência a empreendedores imigrantes ou refugiados são a Small Business Administration, os órgãos municipais de desenvolvimento de negócios, e, dependendo de sua raça ou etnia, alguns proto-empreendedores podem se aproveitar de órgão estaduais criados para minorias específicas. Em Massachusetts, por exemplo, o Órgão Estadual para Assistência a Negócios de Minorias e Mulheres (State Office of Minority and Women Business Assistance) promove desenvolvimento de negócios e organizações sem fins lucrativos de propriedade de negros e mulheres. Mas há estudos que demonstram que as agências de apoio da sociedade não têm sido muito bem-sucedidas em seus esforços de atingir a comunidade de negócios de minorias para a oferta de apoio financeiro e educacional. Com isso, os empreendedores vêm recebendo muito pouca assistência dessas agências. Alguns estudos demonstram que é mais provável que recorram a canais informais em busca de ajuda, normalmente igrejas, suas comunidades de compatriotas, seus pares em negócios semelhantes ou, com menor freqüência, outras linhas de atividade.
O caminho empreendedor é tão largamente reconhecido como uma chave crucial para a adaptação bemsucedida de novos imigrantes, que têm surgido livros e brochuras de instrução oferecendo maior assistência a recém-chegados que desejem estabelecer seu próprio negócio. Um exemplo recente é The Complete Success Guide for the Immigrant Life (Glendale, CA: PDI Books, 2004), de Monette Adva Maglaya, que inclui um capítulo detalhado sobre a abertura de um negócio, com informações fundamentais quanto ao papel central do auto-emprego no sistema socioeconômico americano. Concentra-se na região sul da Califórnia, tida como solo especialmente fértil para pequenos negócios. A autora inclui estudos de caso de grupos de imigrantes com forte histórico de sucesso empreendedor, como os recém-chegados coreanos e chineses. Grande parte do capítulo inclui conselhos práticos para criar um plano de negócio, levantar o capital inicial, escolher um sócio e um tipo societário, onde instalar o estabelecimento, como atribuir preço a produtos e serviços e, finalmente, como anunciar.

Em sua discussão sobre a vitalidade do empreendedorismo coreano, Maglaya destaca os recursos culturais transplantados por esse grupo. Um deles é uma associação de crédito rotativo, conhecido como sistema kye, onde os coreanos recém-chegados podem obter capital para o estabelecimento de negócios pedindo ajuda a amigos e parentes que já estejam bem instalados. Principalmente como postura defensiva contra a discriminação, os empreendimentos coreanos unem-se a suas próprias associações comerciais e preferem negociar entre si. Mas há tendências que indicam que alguns se aventuram para além das redes de negócios coreanas, explorando outros mercados étnicos e também parte do mercado principal, enquanto expan- 
dem agressivamente sua gama de atividades, passando a incluir serviços jurídicos, contábeis, bancários, imobiliários e de seguros.

Os imigrantes coreanos e chineses são particularmente conhecidos por essas redes de crédito rotativo, mas não são, de forma alguma, os únicos grupos que dispõem desse tipo de vantagem cultural. Associações desse tipo são comuns em todo o mundo, desde outros países asiáticos, como o Japão, até o Senegal, na África ocidental, ou Trinidad, no Caribe, e as evidências sugerem que, ao criar tais associações em comunidades de diáspora, os imigrantes normalmente estão adaptando ou recriando uma prática nativa. Com efeito, alguns estudiosos descrevem esse sistema de crédito como banco indígena. Com toda a sua diversidade geográfica, as associações de crédito costumam operar de acordo com um mesmo princípio básico: seus membros contribuem com um valor fixo a cada reunião e o distribuem alternadamente aos participantes. Mas essas organizações fazem muito mais do que apenas conceder crédito. Ao ritualizar a autoajuda, encorajam a poupança, incentivam a solidariedade étnica e servem como trampolim para a participação étnica na arena política mais ampla.

Esse tipo de atividade bancária ajudou muitos imigrantes a se adaptarem economicamente bem à sua nova situação. A faceta mais vantajosa do sistema está em servir como banco étnico, em que os imigrantes, muitas vezes membros de minorias raciais pobres, podem obter crédito sem a burocracia das instituições financeiras formais. As associações de crédito rotativo agem principalmente como um mecanismo econômico transplantado para os imigrantes de primeira geração e não necessariamente como um pálio duradouro de identidade étnica. Ainda assim, a prevalência de associações de crédito rotativo entre comunidades de imigrantes economicamente bemsucedidas tem atraído considerável atenção acadêmica. Alguns afirmam que é justamente esse sistema de empréstimos rotativos o fator central para o êxito empreendedor, e chegam a explicar as diferentes taxas de sucesso dos vários grupos de imigrantes segundo eles tenham ou não tradição em tais recursos transplantados. Mas, mesmo onde há tais redes, as famílias muitas vezes concedem empréstimos maiores e em melhores condições do que os membros co-étnicos de associações de crédito.

Dessa forma, em vez de ensinar empreendedorismo aos imigrantes, podíamos certamente inverter a proposição e nos perguntar o que os imigrantes têm a nos ensinar sobre isso. À medida que os pesquisadores e acadêmicos desenvolvem estruturas e currículos de ensino para os estudantes de empreendedorismo, especialmente como preparação para a fundação de pequenas e médias empresas, podem muito bem descobrir que alguns dos mais comprovados métodos para começar e expandir empresas de sucesso há muito vêm sendo agregados aos negócios étnicos e de imigrantes, como a associação de crédito rotativo, por serem úteis ferramentas pedagógicas.

Permitam-me virar mais uma vez a mesa e discutir o impacto da imigração em grande escala sobre o modo de os americanos fazerem negócios, o que pode sugerir modificações na educação para o empreendedorismo de modo a refletir essas mudanças. Num mundo globalizado, em que cada vez mais os estados-nações se tornam sociedades de crescente diversidade cultural, a necessidade de treinar empreendedores para abarcar esses mercados passa a ser cada vez mais forte.

Após trabalhar com o empreendedorismo imigrante, ficou mais fácil desenvolver meu próximo projeto, um estudo da relação mutante entre a formação da identidade étnica e a moderna cultura de consumo nos Estados Unidos do final do século XX. A tentativa de unir o estudo do consumismo moderno com o da identidade étnica envolve o mapeamento de novos territórios. Embora a literatura sobre etnia seja vasta, trabalhos sérios relacionados à natureza do consumo ainda estão em seus estágios iniciais, e costumam ser encontrados na periferia da investigação sociocultural. Isso não significa que não haja pesquisas que liguem o autointeresse econômico com a dinâmica cultural. Pelo contrário, o campo do empreendimento étnico, como já inferimos, ostenta literatura bem desenvolvida e representa, talvez, a abordagem mais explícita dessa inter-relação, ao explorar como o empreendedorismo, em particular a história dos empreendimentos imigrantes, se situa dentro da economia étnica. Ainda assim, com poucas e honrosas exceções, o papel do imigrante como consumidor tem sido ignorado.

Em Shopping for Identity: The Marketing of Ethnicity (New York: Schocken Books, 2000), estudei a apropriação da etnicidade por empresas, sejam elas de base étnica ou não, como estratégia para vender em mercados mais amplos nos Estados Unidos. Se repararmos bem, o marketing étnico e a revitalização étnica que o alimenta estão por toda a parte. Nos corredores de qualquer supermercado dos Estados Unidos encontramos mais salsa do que ketchup. As vendas de tortillas crescem mais rápido que vendas de pão. A variedade de alimentos encontrados no comércio não é apenas o reflexo da diversidade étnica americana, mas também a evidência de uma mudança recente, porém profunda, em relação ao modo como os americanos se vêem, ao que significa ser americano. Nos últimos anos, políticos e cientistas sociais têm procurado determinar se os imigrantes 
de hoje se adaptam à sua terra adotiva com fizeram as gerações anteriores. Mas parecem ignorar outra pergunta de igual importância: como os Estados Unidos têm se adaptado aos hábitos de seus imigrantes? As tendências publicitárias demonstram que a etnia é um forte combustível, alimentando a livre iniciativa e moldando nossos padrões de consumo.

A mudança é abrangente. As empresas americanas hoje gastam mais de US\$ 2 bilhões por ano em publicidade criada para atrair a atenção de novos imigrantes e fidelizar clientes das minorias, cujo poder aquisitivo está estimado em mais de US\$ 1 trilhão ao ano e que anseiam por comprar os sinais de sua herança cultural. O mercado existe. Há hoje mais de 38 milhões de hispânicos, 35 milhões de negros e 11 milhões de asiáticos nos Estados Unidos. São populações em acelerado crescimento e que, como demonstram os dados, vêm enriquecendo. Por exemplo, o Censo de 2000 não só revelou que o crescimento da população latina superou as projeções dos especialistas, mas também demonstrou que a renda familiar média real cresceu $13 \%$, enquanto seu poder de compra total hoje se equipara ao PIB do México. Da mesma forma, os americanos asiáticos, dois terços dos quais nascidos no exterior, representam uma das populações de mais rápido crescimento nos Estados Unidos e ocupam a posição mais elevada entre todos os grupos, inclusive o dos brancos, em termos de renda familiar média e atividade empreendedora. Não é de estranhar que hoje as fraldas Pampers, da Procter and Gamble, venham em caixas escritas em inglês e espanhol, que os americanos asiáticos apareçam em comerciais de TV de todos os tipos de produto, desde canetas Parker até entregas pela UPS. A Gerber criou uma linha de alimentos de bebês para famílias hispânicas, a Gerber Tropicals, que apresenta novas variedades, como manga, papaia e arroz com feijão, para o gosto deles e apelo nutricional para bebês de todas as etnias.

Sempre me interessei tanto pelo papel do marketing étnico em empresas mais localizadas quanto pelo nível corporativo, e tanto pelos setores não lucrativos da economia como pelos lucrativos. Por gerações, nos Estados Unidos, a empresa étnica tem servido de modelo à fusão entre comércio e cultura, fundamental para a abordagem de marketing como segmentação. Tomemos o exemplo da Arthur T. Gregorian Oriental Rugs, Inc., um negócio familiar armênio-americano localizado em Newton, Massachusetts (seu logo diz: "Um pedacinho da Pérsia em Newton Lower Falls"). Essa empresa vem operando com sucesso desde 1934 e ilustra perfeitamente como a cultura pode ser intrínseca à expertise de negócios num empreendimento étnico local. Embora um amplo conhecimento das tradições armênias de confecção de tapetes tenha sido sempre a base da empresa, nos últimos anos o reconhecimento de uma generalizada demanda de autenticidade, especialmente entre os consumidores da classe média e alta, junto a uma maior apreciação do conhecimento local, levou os proprietários a destacar a riqueza da herança armênia em sua publicidade, inclusive com lances que enfatizam a educação cultural como um bônus adicional ao se comprar na Gregorian. Já na terceira geração, o fundador Arthur Gregorian confiou os negócios a seu filho John, atual presidente, para poder se dedicar em tempo integral ao lado educacional da empresa. Além de publicar bons livros sobre tapetes orientais, Arthur Gregorian profere palestras sobre o assunto e sobre a história da cultura armênia. Sua neta, Melissa, também assumiu o papel de educadora. Nos anúncios de rádio da loja, após informar os ouvintes da variedade e qualidade de suas mercadorias, John Gregorian proclama orgulhosamente a expertise de sua filha e sua disponibilidade como palestrante para oferecer treinamento em confecção de tapetes e tradições armênias a escolas elementares. Os consumidores são incentivados a comprar na Gregorian e aproveitar as oportunidades educacionais oferecidas. Enquanto Arthur escreve para sérios colecionadores de arte, Melissa escreveu uma história para crianças e concebeu um livro de colorir sobre a arte de fazer tapetes. A loja se tornou um centro educacional visitado por alunos de todas as idades, do primeiro grau à educação para adultos. No processo de ensino da história da tecelagem de tapetes, alguns intérpretes fornecem informações sobre o desenvolvimento da cultura armênia, sempre com o objetivo de despertar interesse no aluno ou nos parentes para que se tornem clientes. Os Gregorians se adaptaram ao anseio contemporâneo por representações físicas de culturas autênticas, transformando-se em mais do que simples vendedores de tapetes. São também autoridades acadêmicas que contribuem para a educação multicultural com seus ensinamentos não apenas sobre a arte da tapeçaria, mas também sobre a pouco conhecida história cultural da diáspora armênia, narrativas literalmente entrelaçadas com as próprias mercadorias ofertadas.

Se analisarmos as estratégias que os empreendimentos étnicos tradicionais sempre usaram para atender a uma clientela co-étnica, seja fazendo negócios em sua língua nativa seja utilizando a imprensa étnica, aproveitando possibilidades de publicidade dentro do calendário de eventos da comunidade compatriota, especializando-se em mercadorias indígenas e serviços culturalmente especificados e fazendo questão de conhecer as preferências que dis- 
tinguem seus consumidores, veremos que os especialistas em marketing corporativo estão simplesmente tentando dominar a abordagem na qual os empreendedores étnicos locais basearam seus empreendimentos. A diferença é que as grandes empresas tentam adaptar essas técnicas para que funcionem em escala muito mais ampla.

Essas tendências demográficas flutuantes inspiraram o estabelecimento de espécies inteiramente novas de negócios e serviços, concebidos para atingir uma base culturalmente diversa de consumidores. O marketing étnico se tornou uma indústria, reunindo peritos dotados do mais adiantado treinamento tecnológico e de avançados métodos de pesquisa para investigar atitudes, cultura, heróis, organizações dignas de confiança e estilos de vida. A necessidade de consciência intercultural tem sido evidente desde as primeiras atividades de marketing internacional. Quando a International Harvester começou a anunciar para mercados estrangeiros, nos primeiros anos do século passado, foi avisada por um vendedor chinês de que a cor vermelha não deveria ser usada nos anúncios porque representava o luto e seria ofensiva. Da mesma forma, em 1913, a companhia de carnes Armour percebeu que precisaria fazer alterações no esquema de cores azul e amarelo de seus rótulos ao começar a vender na Noruega, pois essas eram as cores da bandeira nacional da vizinha Suécia. Embora esses perigos persigam as empresas desde o advento das campanhas mundiais de marketing, apenas nos últimos anos surgiram, na América corporativa, especialistas capazes de lidar com o problema.

E houve erros. Um famoso tropeço de marketing foi o caso Frito Bandito. Provavelmente a Frito-Lay pensava ter um mascote seguro quando, em 1968, introduziu o Frito Bandito em anúncios para a TV e mídia impressa. Usando um sombrero e disparando revólveres, Frito Bandito falava com forte sotaque mexicano e roubava as pessoas para comprar Fritos. De início, a imagem enfrentou poucos protestos, mas em 1969 um grupo de celebridades de Hollywood, entre as quais Ricardo Montalban, formou o Comitê Mexicano-Americano contra a Difamação, uma organização nos moldes da Liga Judaica contra a Difamação, da NAACP (Associação Nacional para o Progresso das Pessoas de Cor) e de outras organizações integracionistas. Lideradas por DJs da estação de rádio KNBC, de Los Angeles, começaram os protestos e uma ameaça de boicote nacional contra os Fritos. Ainda assim, o Frito Bandito gozava de reconhecimento extraordinariamente elevado, e a empresa divulgou informações declarando que suas pesquisas provavam que a maioria dos americano-mexicanos não se sentia ofendida com os anúncios. Mas em 1971 a Frito Lay (de propriedade da Pepsico) recuou e retirou o Frito Bandito do mercado, apesar das vendas surpreendentemente altas. Significativamente, a controvérsia do Frito Bandito provou a crescente capacidade das comunidades étnicas, anteriormente ignorada, de usar sua força econômica, seguindo o exemplo dos boicotes a lojas e estabelecimentos segregados durante o movimento pelos direitos civis. Campanhas de protesto bem-sucedidas como essas forçaram cada vez mais as grandes empresas a se sensibilizarem com o problema dos estereótipos étnicos de maneira inimaginável poucos anos antes.

Os especialistas em marketing étnico de hoje estão aí para ajudar as empresas a evitar gafes interculturais potencialmente embaraçosas e custosas. Eles combinam conhecimento cultural em primeira mão com o conhecimento de marketing americano para proporcionar uma vantagem competitiva a seus clientes. Entre as empresas de marketing multicultural, a diversidade dos quadros internos é muitas vezes crucial para o sucesso da empresa. Dispor de uma força de trabalho que represente as etnias que são os principais públicos-alvo não apenas ajuda a garantir o sucesso de campanhas de marketing intercultural, mas também agrega credibilidade à empresa, especialmente no que se refere às questões de autenticidade. Dois tipos de expertise - proficiência em línguas estrangeiras e profunda compreensão cultural - andam de braços dados. Uma das melhores maneiras de garantir o sucesso na nova América multicultural é se certificar de que sua empresa reflete essa diversidade. Ademais, os mais sofisticados especialistas em mercado-alvo compreendem as limitações de um escopo por demais amplo para audiências multinacionais. Um componente crucial do treinamento de seus quadros é o desenvolvimento de uma consciência das complexas variações intra-étnicas entre os segmentos hispânico e asiático, e da habilidade para repassar esse conhecimento aos clientes. Por exemplo, muito embora os cubanos e os mexicanos sejam classificados como hispânicos por causa da língua que compartilham, na verdade seus históricos socioculturais e seus padrões de colonização nos Estados Unidos são muito divergentes, e exigem abordagens de marketing diferenciadas. As nuances culturais transmitidas em treinamentos empresariais do setor corporativo poderiam ser transplantadas para as salas de aula, fornecendo aos nascentes empreendedores as ferramentas culturais necessárias para tocar negócios bem-sucedidos no mercado multiétnico e multirracial.

Apenas nos últimos anos, em resposta a essas tendências, pela primeira vez foram feitas alterações curriculares para incorporar os ensinamentos do marketing multicultural e alcançar melhor as crescentes populações de 
novos imigrantes. Ao mesmo tempo, os especialistas têm publicado obras para ajudar a atingir essas metas educacionais. O primeiro livro-texto do gênero, Advertising and Marketing to the New Majority (Wadsworth Publishing, 1994), de Gail Baker Woods, trata das disciplinas de Publicidade e Marketing em sua relação com consumidores étnicos, principalmente afro-americanos, hispano-americanos, ásio-americanos e americanos nativos. Ensina-se os alunos a entenderem os princípios da publicidade e do marketing aplicando-os aos grupos étnicos. O texto foi redigido para instruir por meio de exemplos. Usando estudos de caso de empresas como Kraft, General Foods, Toyota, Metropolitan Life, Scott Paper e Honda, os alunos têm a oportunidade de ver como os peritos do setor lidam com os problemas. Nem todos os casos estudados foram bem sucedidos, o que dá aos alunos uma chance de discutir, analisar e modificar campanhas fracassadas com base no conhecimento adquirido com experiências bem-sucedidas. Outros exemplos de títulos que prometem expertise na abordagem a consumidores multiétnicos são Marketing and Consumer Identity in Multicultural America, de Marye C. Tharp (Sage Publications, 2001), Marketing to American Latinos (Paramount Market Pub, 2002), de M. Isabel Valdes, e The New Mainstream:
How the Multicultural Consumer is Transforming American Business, de Guy Garcia (Ravo, 2004).

Enquanto cada vez mais ofertas de cursos nos campos de Administração de Empresas e Comunicação incorporam unidades de marketing étnico, há dois anos, na Florida State University, um professor empreendedor, Felipe Korzenny, fundou um Centro de Estudos de Comunicações de Marketing Hispânico (Center for the Study of Hispanic Marketing Communications). Korzenny, que trabalhou no setor privado à frente da Cheskin Research, uma empresa de marketing multicultural, reconheceu que o setor de marketing hispânico dos Estados Unidos passara por crescimento dinâmico e, conseqüentemente, necessitava de profissionais treinados, mas que a maioria das organizações de publicidade, agências de relações públicas e organizações de marketing tinham dificuldades para preencher vagas de marketing hispânico. Foi por isso que Korzenny criou o centro, para treinar alunos que atendessem ao setor de marketing hispânico e a profissionais que já trabalham com esse mercado.

Embora minhas pesquisas tenham se concentrado nos Estados Unidos, outros modernos países desenvolvidos, como a Grã-Bretanha, a Holanda, a França, a Alemanha e o Canadá, tam- bém passam por mudanças demográficas que os têm tornado mais diversos do que nunca - e o mercado também reagindo nesses locais. Ademais, os últimos recém-chegados, diferentemente das ondas de imigrantes anteriores, têm muito maior chance de ter sido expostos a produtos americanos em seus países de origem, diretamente ou por meio da mídia global, já que o marketing de mercadorias dos Estados Unidos tem se tornado cada vez mais internacionalizado. Assim como se diversificam as populações de muitos países, também os estudos de caso, as consultas com empreendedores, os palestrantes convidados e as leituras dos programas de educação para o empreendedorismo podem refletir a diversificação cultural do mundo dos negócios. Seja ensinando empreendedorismo a imigrantes ou a cidadãos natos, a empresários experientes ou à geração mais jovem, reconhecer essas mudanças populacionais e incorporar o conceito de cultura reforçará a abordagem pedagógica nas salas de aula de empreendedorismo.

\section{NOTA}

Esta pensata é uma adaptação da conferência proferida pela autora no evento "Internationalizing Entrepreneurship Education and Training: Innovative Formats for Entrepreneurshirp Education Teaching", ocorrida na FGV-EAESP em julho de 2006.

Artigo convidado. Aprovado em 09.10.2006.

\author{
Marilyn Halter \\ Professora de História e pesquisadora do Institute on Culture, Religion and World Affairs \\ (CURA) - Boston University. \\ Interesses de pesquisa nas áreas de estudos americanos, história e sociologia da imigração, \\ etnicidade, história cultural americana dos séculos XIX e XX, e história do consumidor. \\ E-mail: mhalter@bu.edu \\ Endereço: Boston University, 226 Bay State Rd. Rm. 101, Boston - MA, 02215.
}

